\title{
O SEXO, O GÊNERO E AS PESSOAS TRANSGÊNERAS
}

\section{LETÍCIA LANZ ${ }^{1}$}

O reconhecimento da existência de dois sexos biologicamente diferenciados na espécie humana é um fato muito recente na história da civilização. Até a entrada do século XIX, homens e mulheres eram considerados seres pertencentes a um único sexo: o sexo masculino. A fêmea simplesmente não existia como categoria biológica, sendo, até então, considerada como um "macho encruado", cujo aparelho genital não teve força suficiente para exteriorizar.

Desenvolvida por Cláudio Galeno, médico e filósofo romano de origem grega, e provavelmente o mais talentoso pesquisador da medicina na antiguidade clássica, a tese de que a fềmea não passava de um "macho encruado" vigorou solene, soberba e inquestionável até meados do século XVIII. Examinando a aparência externa dos órgãos genitais masculinos e comparando-os com a aparência interna dos órgãos genitais femininos, Galeno concluiu que vertido para dentro, o escroto seria o útero e os testículos, os ovários, um de cada lado do útero. Por sua vez, o pênis vertido para dentro, também não seria mais do que a vulva e a vagina. Ou seja, o aparelho genital da mulher nada mais era do que o aparelho genital masculino vertido "para dentro" - ou que não teve força suficiente para sair para fora.

$\mathrm{Na}$ visão de Galeno, que prevaleceu por quase dois mil anos, as fêmeas possuíam os mesmíssimos órgãos sexuais que os machos, ou seja, homens e mulheres pertenciam a um mesmo e único sexo, com a diferença das mulheres terem esse sexo menos desenvolvido do que os homens. A mulher era apenas um homem "com menos potência”, um macho subdesenvolvido. Isso é atestado pelas descrições e ilustrações de livros renascentistas de anatomia, assim como pelos termos idênticos com que eram denominados tanto os órgãos genitais masculinos quanto os femininos.

\footnotetext{
${ }^{1}$ Psicanalista, Especialista em Gênero e Sexualidade pela UERJ e Mestra em Sociologia pela UFPR. Poeta, Escritora e Pensadora. Fundadora do Movimento Transgente. Para conhecer mais acesse: Blog: www.leticialanz.blogspot.com.br. Canal YouTube: https://www.youtube.com/user/Lelanz100
}

Rev. Diversidade e Educação, v. 5, n. 1, p. 13-23, jan./jun. 2017. 
Não é difícil perceber o quanto essas "ideias científicas" apenas espelhavam - e respaldavam - a ordem sociopolítica vigente na época, como, aliás, de modo nem um pouco mais sutil, continua acontecendo nos dias atuais. Conforme Foucault (1982), grandes teses da medicina em geral apenas refletem e corroboram as crenças e os valores da ordem vigente no momento em que foram formuladas.

Num claro exemplo de como a cultura se impõe soberana e absoluta sobre a natureza, através de seus complexos mecanismos históricos de cunho sociopolítico e cultural, o modelo do sexo único permaneceu válido e inquestionável por mais de dezoito séculos. Nem a descoberta da próstata, no homem, e do clitóris, na mulher, nem as evidentes e notórias diferenças de "fluídos corporais" entre um e outro ou a notória diferença entre o tecido da parede uterina com o tecido da bolsa escrotal foram suficientes para abalar a ideia de que existia apenas um sexo: o sexo macho.

Até meados do século XVIII, havia somente um único sexo biológico e dois "sexos sociais": o masculino e o feminino, que ainda não eram conhecidos como gênero, mas que, tal como hoje, compreendiam papéis, obrigações e direitos amplamente distintos entre pessoas de sexo macho e fêmea.

Dado que só havia um sexo em gradações distintas de potência, em rigor, não era o pênis, ou a ausência dele, que determinava o sexo a que o indivíduo pertencia. Mas era evidente que possuir um pênis externo assegurava ao sujeito, direitos e privilégios sobre quem não tinha sido capaz de desenvolver um pênis exteriormente, ou seja, alguém cujo pênis tinha ficado "encruado" do lado de dentro.

Diante do exposto, não se pode afirmar de maneira alguma que as diferenças anatômicas naturais entre machos e fêmeas da espécie humana tenham sido responsáveis pelo estabelecimento das diferenças sociopolíticas até hoje existentes entre homens e mulheres, como a grande maioria das pessoas ingenuamente acredita e defende. Simplesmente, porque essas diferenças nem sequer existiam, ou melhor, a sua existência não era nem reconhecida, nem legitimada.

Foram, portanto, condições políticas, econômicas e sociais - muito objetivas que determinaram a supremacia histórica do macho sobre a fêmea, configurada na milenar hierarquia até hoje existente entre os sexos e que se estende, inexorável, para o domínio do gênero. Também não é por simples acaso que as relações de poder do macho sobre a fêmea, tidas como perfeitamente naturais e totalmente desejáveis do Rev. Diversidade e Educação, v. 5, n. 1, p. 13-23, jan./jun. 2017. 
ponto de vista humano e, principalmente, divino, só começaram a ser questionadas a partir de meados do século XVIII no rastro do tsunami político-social da Revolução Francesa.

É a partir desse momento histórico que as relações entre homens e mulheres, baseadas numa suposta superioridade de um sobre o outro, começaram a ser questionadas e paulatinamente substituídas pela ideia da existência de "diferenças sexuais" entre "eles" e "elas". Até então, como mostramos anteriormente, "eles" e “elas" eram uma coisa só.

Com a alteração da ordem sociopolítica puderam ser questionadas as ideias de Galeno, que por séculos sustentaram o isomorfismo entre os machos e as fêmeas da espécie humana, assim como as metáforas religiosas e culturais especialmente construídas para explicar e justificar a superioridade masculina a partir da sua anatomia.

Somente com a chegada do século XIX, os órgãos reprodutivos da mulher passaram a ter nomes próprios e exclusivos deixando de ter os mesmos nomes de órgãos da anatomia masculina. Mas foi preciso esperar mais um século até que as mulheres se reconhecessem como sujeitos da sua própria história e lutassem para serem vistas como uma categoria própria, diferente dos homens, mas com direitos idênticos a eles - e não apenas como "machos menos potentes" que devessem submeter-se aos "machos potentes".

Essa introdução teve por objetivo mostrar que a "zelosa" divisão dos seres humanos em homens e mulheres, rigidamente divididos e classificados nesses dois grupos em função do seu órgão genital, é algo absolutamente recente na história da humanidade.

Desde criança somos condicionados a acreditar, sem nenhum questionamento, que as características e os comportamentos de um homem e de uma mulher, irremediavelmente distintas e até mesmo incompatíveis na maioria dos seus aspectos, são herdados biologicamente e, portanto, atributos naturais que não podem ser modificados.

A despeito dessa crença cultural arraigada, as pesquisas mais recentes têm indicado exatamente o contrário, provando insistentemente que são mínimas as diferenças entre as características e os comportamentos do homem e da mulher. As

Rev. Diversidade e Educação, v. 5, n. 1, p. 13-23, jan./jun. 2017. 
poucas diferenças que poderiam ser consideradas naturais entre machos e fêmeas estariam praticamente restritas ao campo anatômico e fisiológico.

Na prática, cada pessoa é estimulada desde o seu nascimento ou até mesmo antes disso, quer dizer, ainda no útero da mãe, a desenvolver certas características e atributos em função da categoria de gênero - homem ou mulher - em que está classificada, em função do seu sexo biológico de macho ou de fêmea. $O$ homem é estimulado a se desenvolver fisicamente quanto a ter iniciativa, liderança, capacidade empreendedora e agressividade devendo, ao contrário, reprimir manifestações de delicadeza, ternura e sensibilidade. Já a mulher é estimulada a ser dócil, cooperativa, carinhosa, gentil e cuidadora, devendo reprimir manifestações de força, audácia e arrojo empresarial.

Fica óbvio, então, que a esmagadora maioria das supostas diferenças radicais entre homens e mulheres não é resultado de nenhum determinismo da natureza, mas de intensos e de contínuos processos de aprendizagem social.

Daí a pergunta que se segue: - Se características e comportamentos considerados essencialmente masculinos podem ser encontrados nas mulheres e características e comportamentos considerados essencialmente femininos podem ser encontrados nos homens, por que, então, continuar a defini-los como sendo exclusivamente de homens ou de mulheres? Resposta: Para a manutenção e a continuidade do dispositivo binário de gênero, que divide os seres humanos em homens e mulheres, conferindo-lhes uma série de atributos, prerrogativas e papéis sociais em função da sua genitália aparente.

Para o pasmo geral, as pesquisas também revelam que as variações no perfil de indivíduos do mesmo sexo biológico são incrivelmente maiores e mais expressivas do que as variações verificadas entre indivíduos de sexos biológicos distintos.

$\mathrm{Na}$ realidade, as características individuais, rotuladas pela sociedade como masculinas ou femininas, estão distribuídas indistintamente entre todos os seres humanos, independentemente de terem nascido "machos" ou "fềmeas". Mulheres podem ser fortes e determinadas, assim como os homens podem ser sensíveis e afetuosos. Força e determinação não são atributos exclusivos do homem, como sensibilidade, afetividade e cuidado com o outro, tampouco, podem ser considerados atributos exclusivos da mulher. Em síntese, seria muito mais apropriado chamar todos esses atributos, hoje divididos entre masculinos e femininos, de atributos da espécie humana.

Rev. Diversidade e Educação, v. 5, n. 1, p. 13-23, jan./jun. 2017. 
Não é, portanto, o código genético de natureza biológica, mas o código de gênero, de natureza sociopolítica e cultural que determina o que cada pessoa é, pode e deve ou não fazer ao longo da sua vida, tendo em vista o órgão genital que traz entre as pernas ao nascer.

De fato, os rótulos masculino e feminino limitam tremendamente as possibilidades de expressão, criatividade e progresso emocional e intelectual da espécie humana como um todo, já que a ampla e generalizada caracterização social dos dois sexos (macho e fêmea), resultando em atributos e comportamentos exclusivos de homem e exclusivos de mulher, desencoraja as pessoas de viverem e desenvolverem o potencial natural de cada uma.

Fêmeas biológicas, por essa razão classificadas como mulheres, mas que, entretanto, expressam características consideradas masculinas, encontram muita dificuldade na ocupação de um lugar na sociedade e no convívio com outras pessoas, assim como machos, portanto classificados como homens, mas que expressam características consideradas femininas. Em vez de poderem manifestar livremente suas características e atributos naturais, essas pessoas podem passar a vida inteira lutando desesperadamente para desenvolver características que não possuem, com as quais pouco ou nada se identificam e que dificilmente virão a ter de maneira autêntica, digna e confortável.

Muitas pessoas pensam e dirão que não, mas nos dias de hoje, a repressão ao macho é muito mais sufocante e dolorosa do que a repressão exercida até recentemente sobre a fêmea. Os homens estão tendo que fazer um esforço redobrado para reprimir, de um lado, características pessoais que podem ser consideradas femininas e, de outro, para reforçar características necessárias para serem reconhecidos como "homens machos". Esse drama é ainda maior e mais grave na medida em que a mulher de hoje ocupa praticamente todos os espaços e exerce praticamente todos os papéis e funções existentes na sociedade, deixando dúvidas imensas sobre o que seriam características e papéis masculinos no mundo contemporâneo.

Mas enquanto a sociedade insistir em dividir os atributos e comportamentos humanos entre masculinos e femininos, nossas mentes continuarão sendo treinadas para reconhecer determinados comportamentos e práticas como sendo pertinentes apenas a um dado gênero/sexo específico. Continuaremos acreditando que os machos/homens Rev. Diversidade e Educação, v. 5, n. 1, p. 13-23, jan./jun. 2017. 
devam expor apenas características culturalmente classificadas como masculinas, assim como as fêmeas/mulheres devam expor somente características classificadas como femininas.

As grandes estruturas e instituições sociais - família, escola, trabalho, religião, entre outras - continuarão pressionando, consciente e inconscientemente, direta e indiretamente, para que fêmeas e machos atuem segundo padrões de comportamento que nada têm de genético, embora sejam amplamente vendidos como se fossem determinismos da natureza.

As pessoas continuarão tendo suas mentes embotadas e condicionadas a seguir determinados padrões de conduta considerados masculinos ou femininos, e a desprezar, suprimir e recalcar todo o imenso repertório de variações que poderiam apresentar em seu desempenho individual se fossem simplesmente reconhecidas e respeitadas como PESSOAS HUMANAS, sem nenhuma divisão ou categorização de gênero.

Quando a sociedade reconhecer coragem, iniciativa e liderança como atributos humanos, em vez de considerá-los como sendo traços característicos do homem, muito mais mulheres vão se sentir à vontade para manifestar essas características no seu dia a dia. Da mesma forma, os homens não se envergonharão mais (nem ficarão furiosos...) se alguém lhes disser como estão sendo bondosos, compreensivos, receptivos, calorosos, amáveis, gentis, sonhadores, românticos, emotivos, afetuosos e humanos.

O gênero continua sendo o primeiro e o mais fundamental de todos os rótulos sociais que uma pessoa deve carregar ao longo da vida porque, apesar de todos os avanços alcançados em termos de direitos humanos, ainda é a partir dele que vão ser instalados e que podem ser lidos e interpretados todos os demais rótulos que uma pessoa recebe neste mundo. Não ter um rótulo "oficial” de gênero - homem ou mulher - é desesperador porque corresponde a não ter um lugar no mundo, a ser inclassificável sob todos os pontos de vista: social, cultural, político e econômico.

Por isso, as pessoas abrem mão de serem elas mesmas sem maiores considerações éticas, apenas para que sejam "reconhecidas" como "alguém" inteligível pelos seus pares. Caso contrário, sem o gênero imaginam-se uma espécie de monstro sem nenhuma referência no catálogo da sociedade e, portanto, passível de repulsa, marginalização e exclusão por todos os demais.

Rev. Diversidade e Educação, v. 5, n. 1, p. 13-23, jan./jun. 2017. 
Paradoxalmente, portanto, o gênero destrói implacavelmente todo traço de originalidade existente em uma pessoa, na busca de lhe conceder o direito de ser reconhecida como "pessoa" na sociedade e época que vive. No sentido psicanalítico, a imposição de uma categoria de gênero é, portanto, a primeira (e a mais tenebrosa) castração pela qual passamos na vida.

O dispositivo binário de gênero que divide os seres humanos em homens e mulheres, a partir da sua condição biológica de machos e fêmeas, estabelece e cobra de todos os indivíduos a adesão e o cumprimento de inúmeros "códigos de conduta". Qualquer descumprimento, desvio ou não-conformidade é considerado como séria infração das normas de gênero, sendo os infratores pronta e duramente punidos por suas transgressões.

O código de vestuário (dress code), por exemplo, é um deles. O macho, indivíduo que nasceu com pênis e, por isso, é classificado socialmente como homem, não pode apresentar-se socialmente de unhas pintadas, tendo em vista a interdição do código de vestuário em vigor que restringe o uso de maquiagem às mulheres (fêmeas de nascimento possuidoras de vulva e vagina).

Embora se trate de uma grosseira tolice a interdição do uso de unhas pintadas para homens, junto com inúmeras outras tolices semelhantes, ela constitui a base do que se chama masculinidade. E ferir qualquer uma dessas tolices implica em seríssimas consequências para os infratores.

A transgressão às normas de gênero é vista pela sociedade como crime, desvio, pecado e não-conformidade com o que a ordem político-social vigente considera ser a ordem "natural" das coisas.

Essa transgressão das normas de gênero é a matriz de todas as tormentas vividas pelas pessoas transgêneras ao longo das suas vidas. Se elas se enquadrassem direitinho dentro das respectivas caixinhas de gênero que a sociedade lhes destinou ao nascer em função do seu órgão genital, não haveria punição, não haveria medo de se apresentar socialmente como a pessoa sente que é e não haveria a prática horripilante de alguém ter que viver sem assumir sua orientação sexual, ou seja, no armário.

O prefixo trans de trans-gênero não vem de nada sublime como os termos transcendência, transformação e transbordamento conforme querem as cabeças mais românticas e deslumbradas. Por representar transgressão, a pessoa transgênera é tratada Rev. Diversidade e Educação, v. 5, n. 1, p. 13-23, jan./jun. 2017. 
como "transviada" e "transtornada" pela sociedade, mas, ao contrário, reconhecida e louvada como fenômeno de perfeita transfiguração.

Se existe o preconceito, o estigma, a intolerância e a discriminação é porque o trans de TRANS-GÊNERO vem de TRANSGRESSÃO. Transgressão ao dispositivo binário de gênero que determina o enquadramento das pessoas em um dos dois gêneros oficialmente reconhecidos - homem e mulher ou masculino e feminino - em função do órgão sexual que elas trazem entre as pernas ao nascer.

O diagnóstico de transgênero deve sempre anteceder qualquer outro tipo de diagnóstico, principalmente o de orientação sexual. Uma pessoa pode apresentar características transgêneras sem ser homossexual, isto é, pode ser uma transgressora das formas tradicionais de gênero - homem/mulher ou masculino/feminino - sem ser alguém que deseja manter relações erótico-afetivas com pessoas do seu mesmo sexo biológico.

$\mathrm{Na}$ infância, em especial, os adultos podem confundir - e confundem - a inclinação da criança pelo modelo social de gênero oposto ao seu como sintoma de homossexualidade quando, na verdade, não é possível inferir a orientação sexual de crianças em virtude da sua bissexualidade. Essa condição, normal na infância, não permite concluir qual vai ser a sexualidade "definitiva" da criança (como se houvesse algo que se pudesse chamar de "sexualidade definitiva"...).

Mas a grande maioria dos adultos, pela educação que recebeu, considera gênero como sinônimo puro e simples de sexo biológico. Logo, se alguém manifesta alguma identificação com o chamado gênero feminino será imediatamente classificado e tratado como se quisesse ser uma fêmea biológica com desejo sexual por homens, o que são dois enormes disparates!

Primeiro, porque existem homens efeminados que jamais pensaram em "trocar de sexo" ou transar com outros homens e, segundo, porque há fêmeas biológicas que não têm nenhuma atração por homens, mas por outras fêmeas biológicas. Essa linearidade sexo biológico $\rightarrow$ gênero $\rightarrow$ orientação sexual só existe na norma totalmente esdrúxula - da sociedade patriarcal heteronormativa; jamais na realidade.

Portanto, a grande ameaça que ronda as pessoas transgêneras, além de todas as demais, é a de serem diagnosticadas como homossexuais, antes mesmo de serem identificadas como pessoas transgressoras de gênero.

Rev. Diversidade e Educação, v. 5, n. 1, p. 13-23, jan./jun. 2017. 
Por isso mesmo, continua sendo uma das coisas mais absurdas dentro das chamadas comunidades LGBTs, as pessoas transgêneras (o "T" da sigla) serem pura e simplesmente identificadas e tratadas como homossexuais (gays ou lésbicas) apenas "mais aparecidos e afetados" do que o restante dessa população. Algo que precisa ser veementemente combatido, pois, no limite, pode levar muitas pessoas transgêneras a grandes frustrações e até ao suicídio.

Como eu já citei diversas vezes, TRANSGÊNERO não é uma identidade, mas uma condição sociopolítica-cultural de DESVIO, de NÃOCONFORMIDADE e de TRANSGRESSÃO do dispositivo binário de gênero. Chamamos de CISGÊNERA a pessoa na condição oposta, ou seja, de ADEQUAÇÃO, de CONFORMIDADE e de SUBMISSÃO ao dispositivo binário de gênero.

Identidade de gênero não é resultado de herança genética e muito menos da presença de um órgão genital específico no corpo da pessoa. Identidade de gênero resulta da própria subjetividade de cada pessoa e da sua identificação com os modelos de homem e de mulher propostos pela sociedade. Bastaria, portanto, que a pessoa se reconhecesse dentro de uma identidade para que ela fosse legitimada nessa identidade. Em $95 \%$ dos casos, esse simples autorreconhecimento seria suficiente para resgatar a cidadania das pessoas transgêneras (5\% dos casos de autorreconhecimento podem resultar de distúrbios de personalidade). Hoje, a legitimação automática desse autorreconhecimento ainda não é possível no Brasil, em função da intervenção médicojurídica e da mitologia em torno de "corpos errados", mitologia essa que "patologiza" o desejo - legítimo - de transformação corporal em função da identidade de gênero assumida pela pessoa.

Não é tarefa fácil desconstruir e mudar valores. As pessoas farão sempre o máximo que puderem para manter seus antigos modos de pensar. Mas precisamos caminhar decisivamente para entender cada vez mais o gênero como um grande impeditivo, uma terrível camisa de força imposta à livre expressão da diversidade humana. Estar vinculado a uma determinada categoria de gênero não estimula ninguém a ser o que a pessoa é, mas a ser apenas e tão somente o que estabelece o elenco de conceitos, definições e normas de conduta socialmente fixados para o rótulo identitário que a pessoa carrega ou pretende carregar.

Rev. Diversidade e Educação, v. 5, n. 1, p. 13-23, jan./jun. 2017. 


\section{Referências:}

FOUCAULT, Michel. História da Sexualidade: A vontade de saber. 4. ed. Rio de Janeiro: Graal, 1982.

Obras Consultadas:

ARCHER, John; LLOYD, Barbara Bloom. Sex and gender. New York: Penguin, 1982.

BICCHIERI, Cristina. The Grammar of Society: The Nature and Dynamics of Social Norms. New York: Cambridge University Press, 2006.

BORNSTEIN, Kate. My Gender Workbook. New York: Routledge, 1998.

FAUSTO-STERLING, Anne. Sexing the Body: Gender Politics and the Construction of Sexuality. New York: Basic Books, 2000.

FEINBERG, Leslie. Transgender Liberation: A Movement Whose Time Has Come In (1992). In: STRYKER, Susan; WHITTLE, Stephen. The Transgender Studies

Reader. New York: Routledge, 2006.

FOUCAULT, Michel. História da Sexualidade: A vontade de saber. 4. ed. Rio de Janeiro: Graal, 1982.

GIDDENS, Anthony. As transformações da Intimidade - Sexualidade, Amor e Erotismo nas Sociedades Modernas. São Paulo: Unesp, 1992.

GOFFMAN, Erving. Estigma - Notas sobre a Manipulação da Identidade deteriorada. Rio de Janeiro: Zahar, 1980.

HALL, Stuart. A Identidade Cultural na Pós-Modernidade. Rio de Janeiro: D P \& A, 2001.

JORDANOVA, Ludmilla. Sexual Visions: Images of Gender in Science and Medicine between the Eight-eenth and Twentieth Centuries. The University of Wisconsin Press, 1989.

KIMMEL, Michael. The Gendered Society. New York: Oxford University Press, 2011 .

LAQUEUR, Thomas. Inventando o Sexo - Corpo e Gênero dos Gregos a Freud. Rio de Janeiro: Relume Dumará, 2001.

LE BRETON, David. A Sociologia do Corpo. Petrópolis: Vozes, 2006.

LOURO, Guacira Lopes. Pedagogias da Sexualidade. In: (Org.). O Corpo

Educado - Pedagogias da Sexualidade. Belo Horizonte: Autêntica, 2000.

Rev. Diversidade e Educação, v. 5, n. 1, p. 13-23, jan./jun. 2017. 
STRYKER, Susan. The Transgender Studies Reader. New York: Routledge, 2006.

THURER, Shari L. The End of Gender - A psychological autopsy. New York:

Routledge, 2005.

VALENTINE, David. Imagining Transgender: an ethnography of a category. Durham NC: Duke University Press, 2000.

Recebido em: 25/05/17

Aceito em: 03/07/17

Rev. Diversidade e Educação, v. 5, n. 1, p. 13-23, jan./jun. 2017. 